\title{
Miguel Ángel y el Hígado de Noé: ¿Una Lección Secreta de Anatomía?
}

\author{
Michelangelo and Noah's Liver: A Hidden Anatomy Lesson?
}

\author{
Roberto Ariel Macchiavello Machoํㄹ \& Camila Vilma Bolelli Díaz ${ }^{2}$
}

MACCHIAVELLO, M. R. A. \& BOLELLI, D. C. V. Miguel Ángel y el hígado de Noé: ¿una lección secreta de anatomía? Int. J. Morphol., 37(3):872-876, 2019.

RESUMEN: Miguel Ángel Buonarroti (1475 - 1564) es considerando uno de los más grandes artistas de la historia. Estudió en detalle la anatomía humana a través de la disección de cadáveres, práctica hasta entonces relegada por motivos religiosos. Desde que en el año 1990 el médico Frank Lynn Meshberger publicara su interpretación del fresco "La Creación de Adán” basada en la neuroanatomía, en donde comparaba la imagen de Dios con la de una sección sagital del cerebro humano, muchos autores han encontrado diversas referencias anatómicas ocultas en la obra de Miguel Ángel. En el presente trabajo exponemos el hallazgo de una inédita lección de anatomía hepática oculta en el fresco La Embriaguez de Noé de la Capilla Sixtina.

PALABRAS CLAVE: Hígado; Anatomía; Medicina en las artes; Cirrosis hepática.

\section{INTRODUCCIÓN}

Miguel Ángel Buonarroti (1475 - 1564) fue un escultor, pintor y arquitecto renacentista. Gran conocedor de la anatomía humana, obtenía su conocimiento a través de la disección de cadáveres, práctica relegada desde los tiempos de Galeno (Vasari, 1965; Lynn, 1990; Santos et al., 2013). En palabras de uno de sus biógrafos, Ascanio Condivi, “...trabajó en tantas disecciones humanas que aquellos que han dedicado su vida a la misma y que la han convertido en su profesión apenas saben tanto como él" (Condivi, 1976). Una de sus obras capitales es la Capilla Sixtina, la cual pintó durante los años 1508 y 1512.

Desde que en 1990 Frank Lynn Meshberger publicara su interpretación de la Creación de Adan basada en la neuroanatomía (Meshberger, 1990), en donde comparaba la imagen de Dios con la de una sección sagital del cerebro humano, muchos autores han encontrado diversas referencias de anatomía ocultas en la obra de Miguel Ángel. Eknoyan (2000) describe la forma de un riñón derecho seccionado en el fresco La Separación de las Aguas y la Tierra, asociándolo a la nefrolitiasis que padeció el artista durante su vida y al conocimiento que tenía este sobre fisiología renal. Barreto \& de Oliveira (2004) han llegado a publicar un tratado con diversas referencias ana- tómicas ocultas en 32 escenas de la Capilla Sixtina, lo cual ha derivado también en críticas respecto a cuantas de estas asociaciones tienen un fundamento y cuantas son producto de la imaginación del que las interpreta (Kickhöfel, 2004).

En el presente trabajo exponemos una hasta ahora desconocida lección de anatomía hepática oculta en el fresco La Embriaguez de Noé de la Capilla Sixtina.

\section{MATERIAL Y MÉTODO}

Para la preparación de este trabajo se consultó publicaciones científicas en español, inglés y portugués. Se utilizó una búsqueda en la base de datos Pubmed y Google Scholar usando los términos "Michelangelo", "Anatomy" y "Medicine". Se consultaron los libros de Barreto \& de Oliveira y Tatem (2013), así como textos de arte. El análisis e interpretación del fresco La Embriaguez de Noé fueron realizados por los propios autores de forma original utilizando imágenes de acceso público del sitio Web Gallery of Art (Krén \& Marx, 2018).

\footnotetext{
${ }^{1}$ Servicio de Cirugía Plástica y Quemados, Hospital de Urgencia Asistencia Pública, Santiago, Chile.

${ }^{2}$ Programa de Psiquiatría, Sede Oriente, Universidad de Chile, Santiago, Chile.
} 


\section{RESULTADOS}

Los frescos principales de la Capilla Sixtina representan nueve temas del Génesis. Rodeando cada una de estas escenas bíblicas existen desnudos masculinos en diversas actitudes. Estas figuras son denominadas Ignudi, equivalentes a los ángeles o a los putti del siglo XV. Los Ignudi sostienen guirnaldas hechas de hojas de roble y bellotas, alusiones al escudo de la familia Della Rovere, nobles italianos de la época (Arbour, 1966). La Embriaguez de Noé es uno de los nueve frescos (Fig. 1) y uno de los pocos dañados de la Capilla Sixtina.

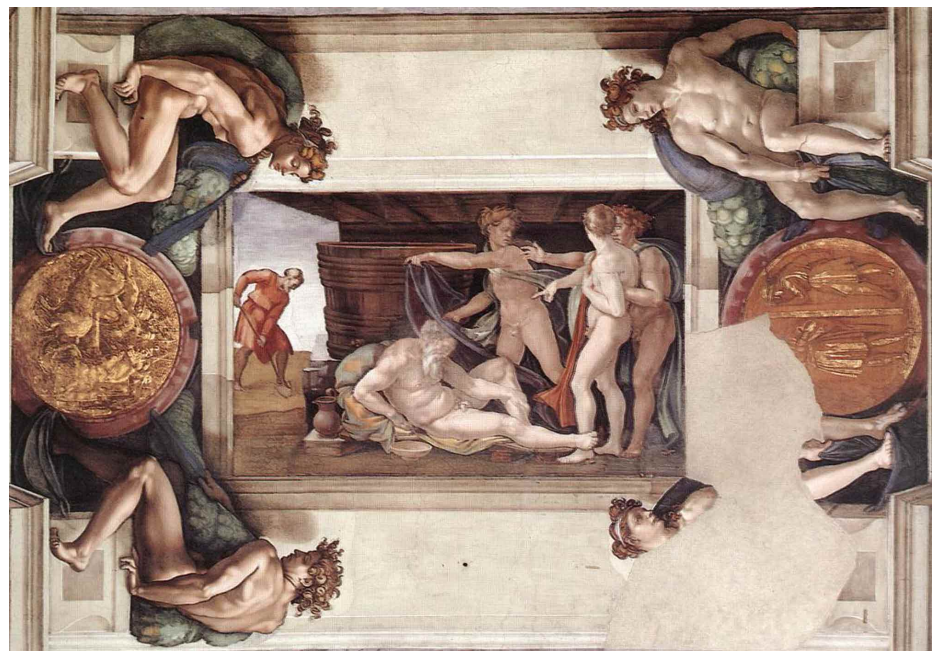

Fig. 1. Fresco La Embriaguez de Noé.

Este fresco hace alusión al siguiente pasaje bíblico: "Noé se dedicó a cultivar la tierra, y plantó una viña. Un día, bebió vino y se embriagó, quedándose desnudo dentro de su carpa. Cam, el padre de Canaán, vio a su padre desnudo y fue a contárselo a sus hermanos, que estaban afuera. Entonces Sem y Jafet tomaron un manto, se lo echaron sobre los hombros, y caminando hacia atrás, cubrieron la desnudez de su padre. Como miraban en dirección opuesta, no lo vieron desnudo" (Génesis 9:20-27). Se distinguen dos escenas. La primera, en donde Noé se encuentra labrando la tierra y en la segunda, Noé embriagado y dormido. Cam avisa a sus hermanos Sem y Jafet, que con su manto tapa la desnudez de su padre.

A nuestro parecer, en La Embriaguez de Noé, Miguel Ángel ha plasmado de manera inteligente y dando muestras de su entendimiento de la anatomía y fisiología humana, referencias a la anatomía del hígado normal y patológico. Hemos decidido presentar nuestros hallazgos dividiéndolos en cuatro puntos para su mejor compresión.

1. Anatomía normal del hígado. Como hemos mencionado, podemos dividir el fresco en dos secciones. La primera en donde se encuentra Noé trabajando la tierra. La segunda, en donde se encuentra Noé ebrio. En relación a la primera sección, se ubican dos de los cuatro Ignudi sosteniendo guirnaldas de hojas de roble y bellota. Estas guirnaldas, especialmente la del Ignudi ubicado en la esquina superior izquierda, se condicen con la anatomía de un hígado visto por su cara inferior o visceral, con la división entre lóbulos derecho, izquierdo, caudado y cuadrado (Fig. 2).

2. Anatomía del hígado patológico. En relación al Noé ebrio, se ubican los dos Ignudi restantes sosteniendo las guirnaldas descritas. Si bien uno de ellos está dañado, la guirnalda del Ignudi que permanece intacto (y que corresponde a una imagen en espejo del anterior según grabados del siglo XVI (Krén \& Marx) se condice con la anatomía de un hígado multinodular típico de la cirrosis, también desde su cara inferior (Fig. 3).

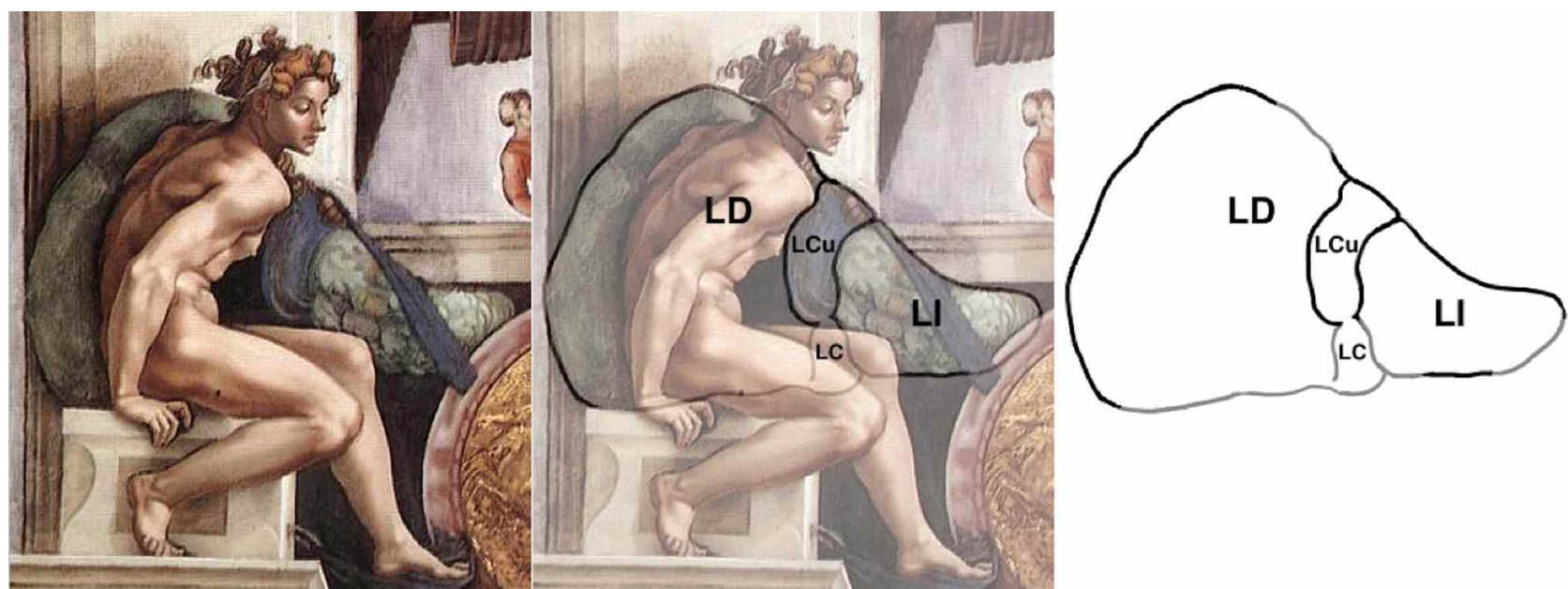

Fig. 2. Hígado visto por su cara inferior, con la división entre lóbulo derecho (LD), izquierdo (LI), caudado (LC) y cuadrado (LCu). 

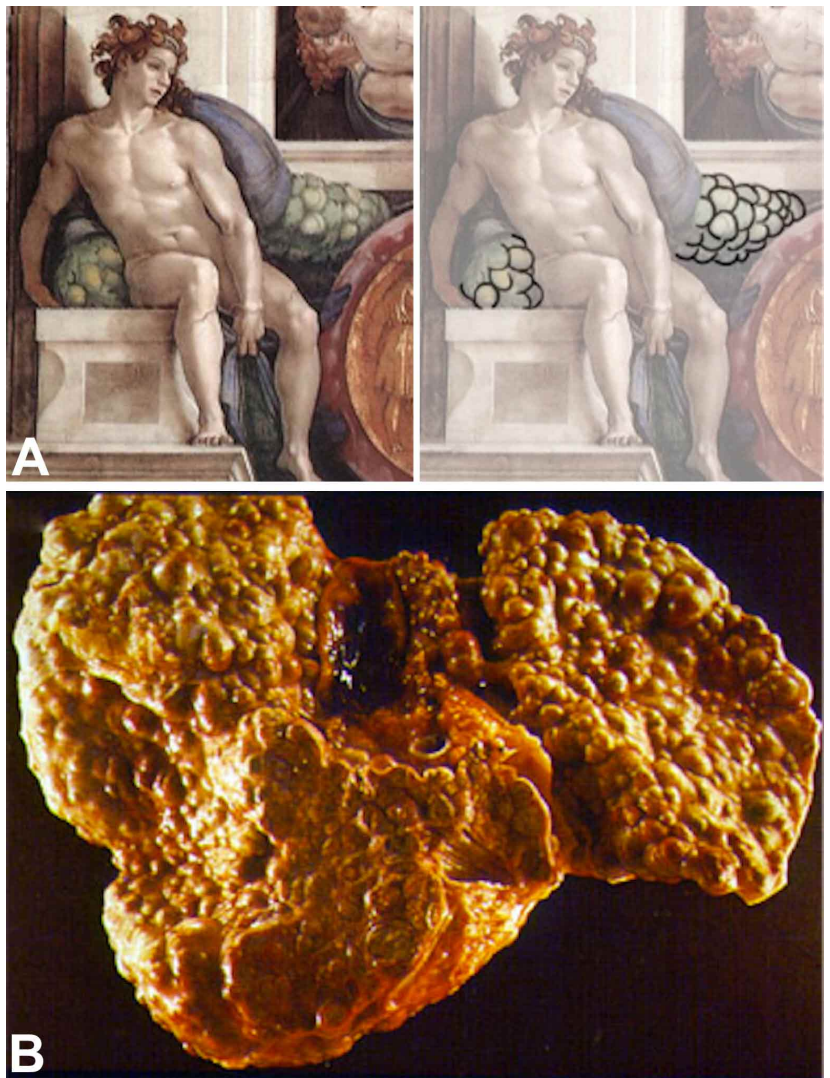

Fig. 3. a. Hígado multinodular cirrótico visto por su cara inferior. Imagen rotada en espejo. b. Anatomía Patológica de Hígado multinodular. Imagen propiedad de University of Pittsburgh Medical Center (UPMC), tomada del sitio: http:// www.pathology.pitt.edu/lectures/gi/liver1-b/index.htm.

3. Alegoría del hígado formada por los hijos de Noé. Cam, Sem y Jafet por medio de sus extremidades y mantos conforman la silueta de un hígado desde una visión posterior, incluído el trayecto de la vena cava inferior y el área desnuda (Fig. 4).

4. Ictericia de los Ignudi. Si comparamos los Ignudi de la sección del Noé trabajando con los Ignudi del Noé ebrio, podemos apreciar que estos últimos tiene un aspecto enfermo y que en sus escleras se aprecia un tinte ictérico. Esta última condición es más clara comparados con Ignudi de otros frescos, los que presentan escleras blancas (Fig. 5).

\section{DISCUSIÓN}

Michelangelo Buonarroti es uno de los artistas más interesantes que jamás halla existido. Gran estudioso de la anatomía humana, comenzó a practicar disecciones de cadáveres humanos a la edad de 18 años (Eknoyan). Esta rela-
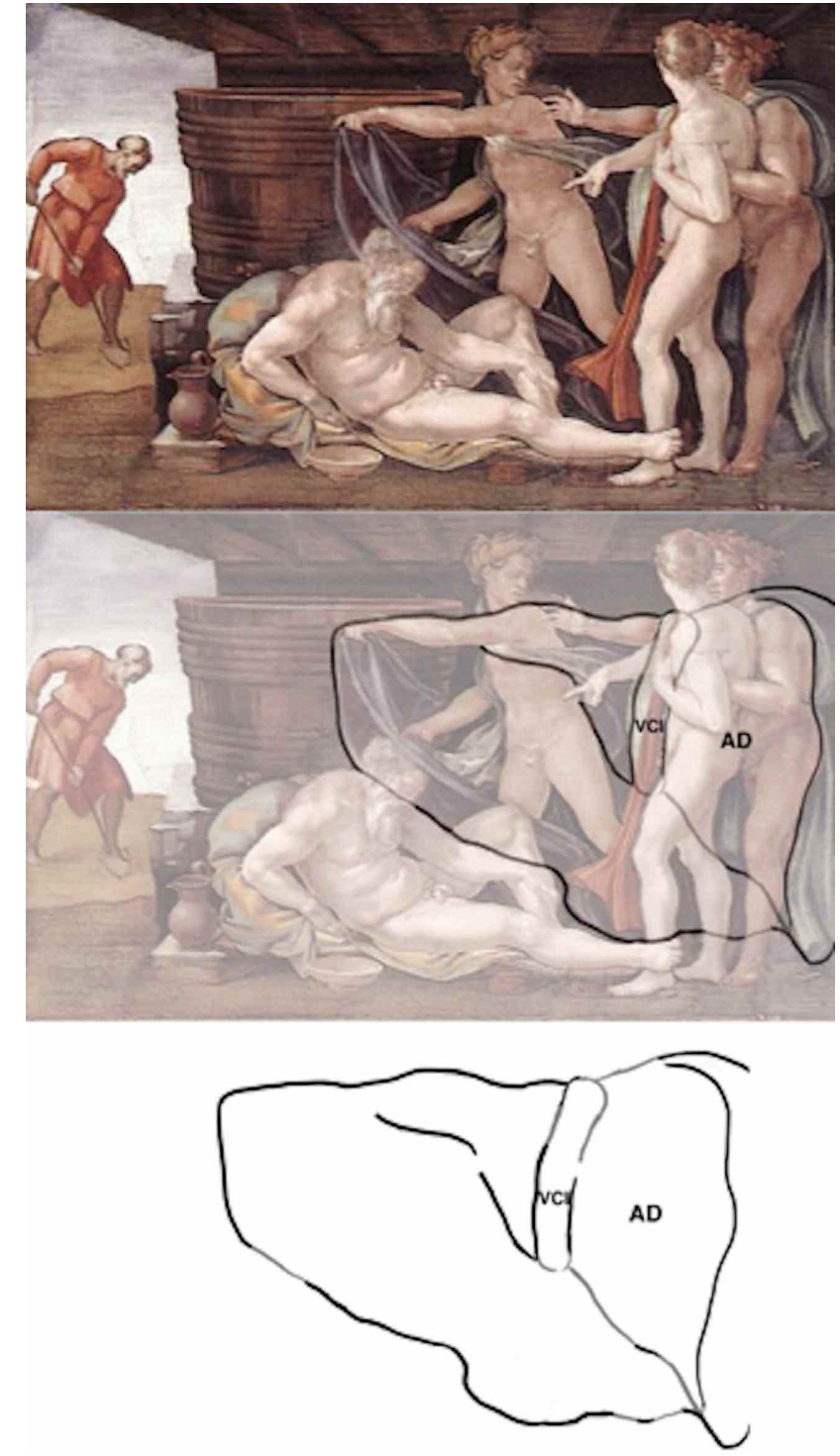

Fig. 4. Hígado desde una visión posterior, incluído el trayecto de la vena cava inferior (VCI) y el área desnuda (AD).

ción con el cuerpo humano fue más allá de la pura forma, sino que también se interesó por la función y la enfermedad. El estudio de anatomía por los artistas de esa época consistía en asistir a disecciones públicas, las que eran conducidas por médicos o cirujanos, impregnándose así del conocimiento científico expuesto por los mismos (Margotta, 1996). Miguel Ángel fue gran amigo de Mateo Realdo Colombo, destacado médico, anatomista y cirujano de la época, con quien planeó escribir un libro colaborativo de anatomía que nunca vio la luz (Condivi, 1976).

Múltiples son las publicaciones que asocian obras de Miguel Ángel con mensajes ocultos respecto anatomía, fisiología y enfermedad. Este punto queda claramente re- 

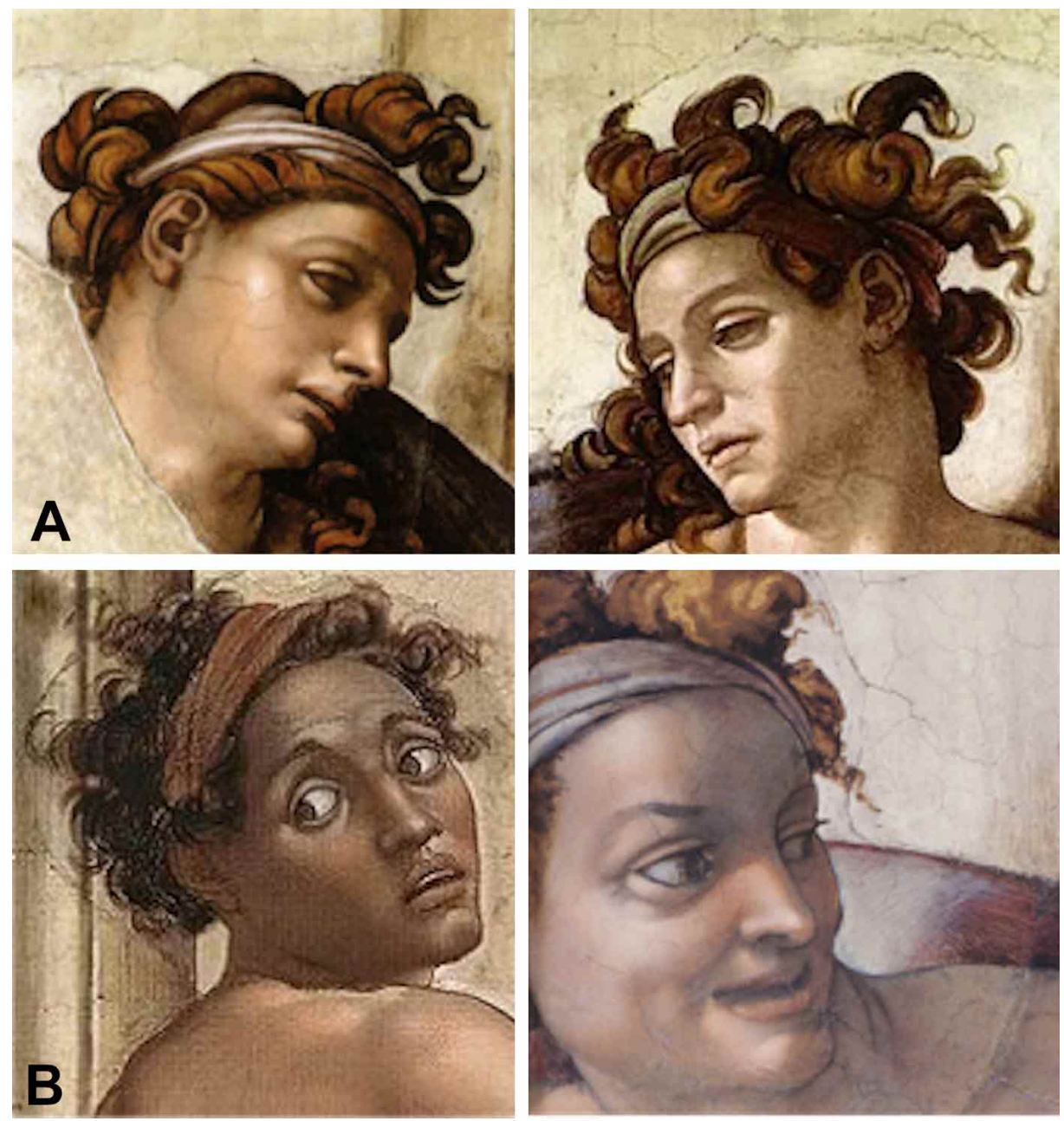

Fig. 5. a. Ignudi del fresco La Embriaguez de Noé con aspecto enfermo y escleras ictéricas. b. Ignudi de otros frescos con escleras blancas.
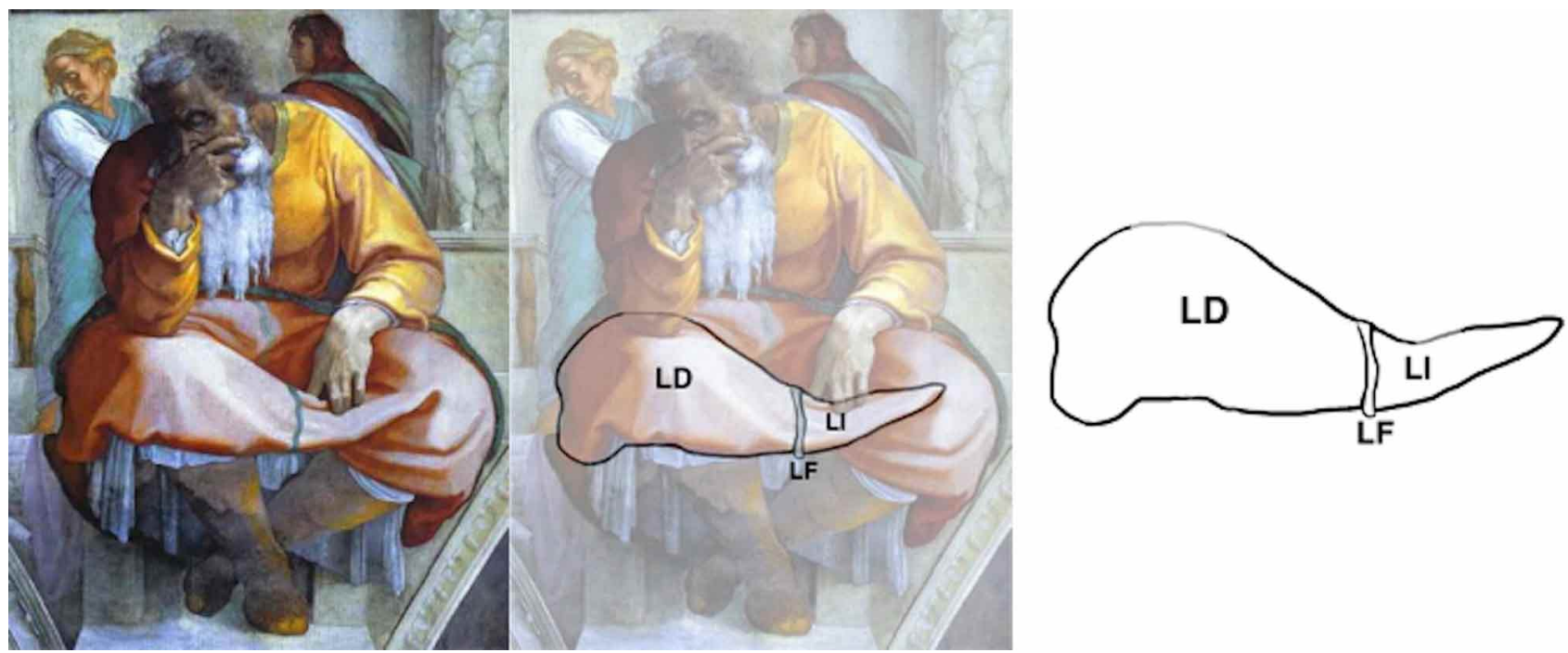

Fig. 6. Hígado desde una visión anterior en el fresco del Profeta Jeremías, descrito por Pellicia (Tatem, 2013). Lóbulo derecho (LD), Lóbulo izquierdo (LI) y Ligamento Falciforme (LF). 
presentado con la interpretación que hacen Stark \& Nelson (2000) de la escultura "La Noche", en donde la mama izquierda de la figura presenta signos de un tumor localmente avanzado, no así su par derecha ni la escultura acompañante "El Amanecer", sugiriendo que Miguel Ángel de forma intencional representó una mujer con esta enfermedad quizás por haber tenido conocimientos de la misma a través de sus disecciones. Además, contrapone la salud (amanecer) y la enfermedad (noche) en una misma obra (Stark \& Nelson). Eknoyan hace referencia a la figura de un riñón seccionado en el fresco "La Separación de las Aguas y la Tierra", sugiriendo que Miguel Ángel era familiar a la función del riñón como era entendida en ese tiempo.

Este principio del conocimiento tanto de la forma como de la función, en este caso del hígado, está presente en los hallazgos expuestos en nuestro trabajo. Miguel Ángel juega con la contraposición de la salud y la enfermedad, así tal como lo hace en "La Noche".

Respecto a la interpretación del fresco La Embriaguez de Noé como una lección de anatomía del hígado, creemos que los argumentos anteriormente expuestos son válidos para defender que esta asociación no es producto de la imaginación de los autores. En este sentido podemos agregar los siguientes argumentos relevantes:

En las guirnaldas de los Ignudi de otros frescos están bien definidas las hojas de robles y bellotas, rindiendo claro homenaje al escudo de la familia Della Rovere. No así en los Ignudi de La Embriaguez de Noé, en los cuales creemos que ha jugado con las texturas y formas de las guirnaldas para asemejarse así a las superficies de un hígado sano y de uno cirrótico. Este punto debiese ser materia de discusión por académicos en arte.

Nos llama la atención la forma del hígado concebida en las imágenes expuestas, particularmente en lo alargado del lóbulo hepático izquierdo. Sin embargo, es interesante saber que esta misma forma del hígado ya había sido descrita previamente por Pellicia (Tatem) en el fresco del Profeta Jeremías, esta vez desde una visión anterior (Fig. 6). En relación la alegoría del hígado formado por los hijos de Noé, publicaciones anteriores, como las descritas por Barreto \& de Oliveira, basan sus interpretaciones en el uso que le da Miguel Ángel a los mantos y vestimentas como herramienta para representar diversos órganos.

Todo esto que se ha expuesto se sustenta además en torno a un eje central del fresco: los efectos que provoca en el hombre la ingesta excesiva de alcohol, registrados ya desde tiempos bíblicos.
Creemos que solo basta con ponerse a mirar de manera curiosa la obra de Miguel Ángel para descubrir los mensaje ocultos a través de los cuales él quizo entregarnos su extenso conocimiento del cuerpo humano.

AGRADECIMIENTOS. A Clara Macchiavello.

MACCHIAVELLO, M. R. A. \& BOLELLI, D. C. V. Michelangelo and Noah's Liver: A hidden anatomy lesson?. Int. J. Morphol., 37(3):872-876, 2019,

SUMMARY: Michelangelo Buonarroti (1475 - 1564) is considered one of the greatest artists in history. He studied in detail the human anatomy through corpses dissection, practice until then relegated for religious reasons. Since the physician Frank Lynn Meshberger published in 1990 his interpretation of the fresco "The Creation of Adam" based on neuroanatomy, where he compared the image of God with a sagittal section of the human brain, many authors have found various hidden anatomical references in the work of Michelangelo. In the present paper we expose the finding of a hidden lesson on liver anatomy in the fresco The Drunkenness of Noah of the Sistine Chapel.

KEY WORDS: Liver; Anatomy; Medicine in the arts; Liver cirrhosis.

\section{REFERENCIAS BIBLIOGRÁFICAS}

Arbour, R. Miguel Angel. Barcelona, Ediciones Daimon, 1996.

Barreto, G. \& de Oliveira, M. A Arte Secreta de Michelangelo. Uma Lição de Anatomia Na Capela Sistina. São Paulo, Editora ARX, 2004.

Condivi, A. The Life of Michelangelo. Baton Rouge, Louisiana State University Press, 1976.

Eknoyan, G. Michelangelo: art, anatomy, and the kidney. Kidney Int., 57(3):1190201, 2000.

Kickhöfel, E. H. P. Uma falsa lição de anatomía ou de um simples caso de impregnação teórica dos fatos. Sci. Stud., 2(3):427-43, 2004.

Krén, E. \& Marx, D. Drunkenness of Noah (with ignudi and medallions). 1509, Fresco, Cappella Sistina, Vatican. Web Gallery of Art, 2018. Disponible en: https://www.wga.hu/html_m/m/michelan/3sistina/1genesis/1drunken/ 01_2ce1f.html

Margotta, R. The History of Medicine. New York, Smithmark Publishers, 1996.

Meshberger, F. L. An interpretation of Michelangelo's Creation of Adam based on neuroanatomy. JAMA, 264(14):1837-41, 1990.

Santos, I. P.; Rosa, J. P. C.; Ellwanger, J. H.; Molz, P.; Rosa-Silva, H. T \& de Campos, D. Michelangelo's art on the Sistine Chapel ceiling: Sacred representation or anatomy lessons? J. Morphol. Sci., 30(1):43-8, 2013.

Stark, J. J. \& Nelson, J. K. The breasts of "Night": Michelangelo as oncologist. N. Engl. J. Med., 343(21):1577-8, 2000.

Tatem, S. Michelangelo's Secret Anatomy Book. Bloomington, Xlibris, 2013.

Vasari, G. The Lives of Artists. Middlesex, Penguin Classics, 1965.

Dirección para correspondencia:

Roberto Ariel Macchiavello Macho

Servicio de Cirugía Plástica y Quemados,

Hospital de Urgencia Asistencia Pública

Avenida Portugal 125

Santiago - CHILE

Recibido : 05-12-2018

Aceptado: 06-02-2019

Email: robertomac89@gmail.com 